\title{
A delayed diagnosis of aortic coarctation
}

\author{
Arthur Davis, $\mathrm{MD}^{\mathrm{a}}$ (D), Joseph Stafford, $\mathrm{MD}^{\mathrm{b}}$, Gibbs Wilson, $\mathrm{MD}^{\mathrm{b}}$, and Steven Costa, MD \\ ${ }^{a}$ Department of Medicine, Baylor Scott \& White Medical Center-Temple, Temple, Texas; 'bepartment of Cardiology, Baylor Scott \& \\ White Medical Center-Temple, Temple, Texas
}

\section{ABSTRACT}

Coarctation of the aorta is most often diagnosed in early childhood, with infrequent recorded presentations of previously undiagnosed adults. We present a young female hospitalized with hypertensive emergency who was then diagnosed with a stenotic bicuspid aortic valve requiring surgical intervention. Subsequent preoperative coronary angiogram led to discovery of an undiagnosed coarctation of the aorta, which is commonly a forgotten cause of secondary hypertension.

KEYWORDS Aortic coarctation; congenital heart disease; secondary hypertension

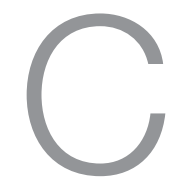

oarctation of the aorta $(\mathrm{CoA})$ is not an uncommon congenital heart anomaly, with an incidence ranging from $5 \%$ to $8 \%$ of all congenital cardiac defects. ${ }^{1}$ The most common presenting sign of unrepaired CoA in adults is hypertension, which is an often overlooked cause of secondary hypertension. Patients with CoA have a higher incidence of associated congenital lesions, and it is reported that more than half of patients with CoA have bicuspid aortic valves. ${ }^{2}$ These patients are also more likely to have cerebral artery aneurysms, with an incidence reported as high as $10 \% .^{2}$ Though classical findings such as diminished femoral pulses may be absent due to collateral circulation in patients who are diagnosed as adults, there should be a delay in timing from brachial to femoral pulsation and weakened amplitude of lower extremity pulse amplitude in comparison to upper extremity on examination. ${ }^{2}$

\section{CASE DESCRIPTION}

A 43-year-old white woman presented with sudden-onset chest pressure and dyspnea on exertion. She had known hypertension (difficult to control), a stenotic bicuspid aortic valve, and a ventricular septal defect (unrepaired). In the emergency department, blood pressure taken in her left arm was $246 / 159 \mathrm{~mm} \mathrm{Hg}$, and her heart rate was 112 beats per minute. She appeared anxious and in moderate distress. A grade 3/6 late-peaking, harsh systolic precordial murmur, which radiated into the carotid arteries, was heard best in the right upper sternal border at the second intercostal space.
There was no peripheral edema and her peripheral pulses were good. Coarse sounds were heard throughout the lungs. Her troponin level was $0.53 \mathrm{ng} / \mathrm{mL}$, and her electrocardiogram disclosed QRS voltage criteria for left ventricular hypertrophy. Intravenous labetalol, hydralazine, and nitroglycerin paste decreased the arm systolic blood pressure to $166 \mathrm{~mm} \mathrm{Hg}$ and eliminated the chest pressure. The repeat troponin level was $0.37 \mathrm{ng} / \mathrm{mL}$.

A transthoracic echocardiogram demonstrated a severely stenotic bicuspid aortic valve (peak velocity $4.6 \mathrm{~m} / \mathrm{s}$ and aortic valve area $0.98 \mathrm{~cm}^{2}$ ). A femoral approach was initially used for her planned coronary angiogram, but the wire could not enter the aortic arch. Aortic angiography via a right radial approach then demonstrated near-total CoA with extensive collateral blood supply to the descending aorta distal to the CoA (Figure 1). Computed tomography angiogram confirmed this diagnosis (Figure 2). The peak-to-peak coarctation gradient was measured at $41 \mathrm{~mm} \mathrm{Hg}$ via transesophageal echocardiogram. Her initial chest $\mathrm{x}$-ray was re-examined, and rib notching was apparent.

The patient then underwent uncomplicated surgical aortic valve replacement, during which balloon angioplasty and stent placement for CoA was performed (Figure 2). Perioperative imaging demonstrated resolution of gradient across the CoA, and she is doing well 2 years postoperatively.

\section{DISCUSSION}

Patients with unrepaired CoA have previously been reported to have a mortality rate of $75 \%$ by the age of 46 ,

Corresponding author: Arthur Davis, MD, Department of Medicine, Baylor Scott \& White Medical Center-Temple, 2401 S. 31st St., Temple, TX 76508 (e-mail: Arthur.davis@bswhealth.org)

Color versions of one or more of the figures in the article can be found online at www.tandfonline.com/ubmc.

Received May 10, 2019; Revised July 15, 2019; Accepted July 18, 2019. 


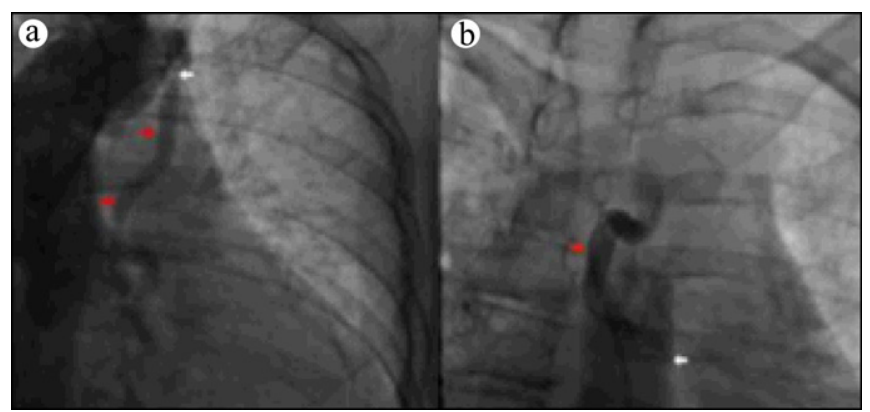

Figure 1. (a) Anterograde injection with extensive collateral circulation highlighted by red arrows; the white arrow indicates the area of coarctation. (b) Hypertrophied collateral flow (red arrow) and descending aorta receiving blood via collateral circulation (white arrow).

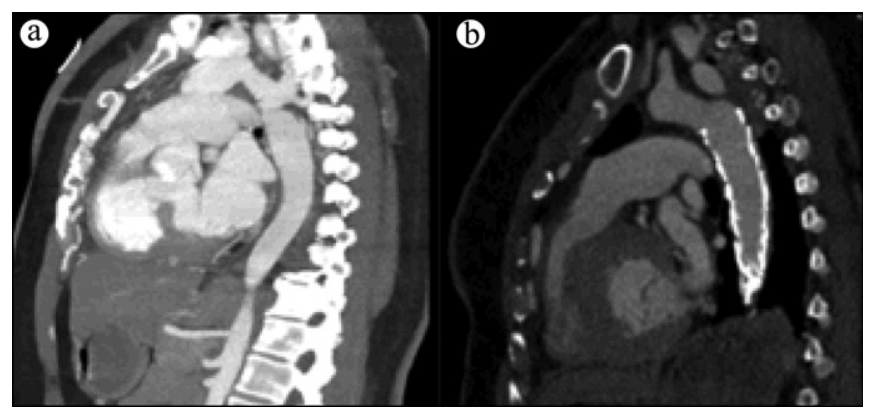

Figure 2. Computed tomography (sagittal view) demonstrating (a) $\mathrm{CoA}$ and (b) successful stent of CoA.

with a mean age of survival of $35 .^{3}$ The pathogenesis of CoA is not well understood, but there are two leading theories: poor development of the aortic arch due to decreased intrauterine blood flow and ductal tissue invasion of the aortic wall during fetal development. ${ }^{4,5}$ In addition to congenital cases, CoA can be acquired from inflammatory diseases such as Takayasu arteritis and, in rare instances, severe atherosclerosis. ${ }^{6,7}$

Indications for intervention in adults include a history of hypertension and evidence of severe $\mathrm{CoA}$ (whether native valve or previously repaired $\mathrm{CoA}$ ). Severe CoA was defined by the 2018 American Heart Association/American College of Cardiology guidelines as

upper extremity/lower extremity resting peak-to-peak gradient $>20 \mathrm{~mm} \mathrm{Hg}$ or mean Doppler systolic gradient $>20 \mathrm{~mm} \mathrm{Hg}$; upper extremity/lower extremity gradient $>10 \mathrm{~mm} \mathrm{Hg}$ or mean Doppler gradient $>10 \mathrm{~mm} \mathrm{Hg}$ plus either decreased left ventricular systolic function or aortic regurgitation; upper extremity/lower extremity gradient $>10 \mathrm{~mm} \mathrm{Hg}$ or mean Doppler gradient $>10 \mathrm{~mm} \mathrm{Hg}$ with collateral flow. ${ }^{2}$

These factors should also be combined with anatomic evidence via cardiac magnetic resonance imaging or computed tomography angiogram. ${ }^{2}$ Following diagnosis, repair via percutaneous intervention or surgical approach is influenced by multiple factors and is determined on a case-by-case basis. ${ }^{2}$

In our patient's case, there were multiple incidences when CoA could have been diagnosed at an earlier age, including her history of extreme hypertension in the setting of previously diagnosed congenital heart defects. It was known that our patient had difficult-to-control hypertension, yet there was no recorded attempt at measuring blood pressure differentials in her upper and lower extremities. She could likely have benefited from earlier intervention had CoA been previously diagnosed. Additionally, had surgery been commenced with no knowledge of this patient's CoA, she likely would have suffered severe complications from being placed on cardiopulmonary bypass due to the subsequent decreased downstream perfusion from her CoA.

Though CoA is a rare presentation in adults, it should remain part of the workup for secondary hypertensionparticularly in patients with a history of congenital heart defects. All patients with suspected CoA should have pressure differentials in the upper and lower extremities assessed. ${ }^{2}$ If $\mathrm{CoA}$ is diagnosed in adults, intervention should be pursued with a multidisciplinary approach (percutaneous repair versus surgical approach) to repair the lesion. ${ }^{2}$

\section{ORCID}

Arthur Davis (D) http://orcid.org/0000-0003-4687-5024

1. Teo LL, Cannell T, Babu-Narayan SV, Hughes M, Mohiaddin RH. Prevalence of associated cardiovascular abnormalities in 500 patients with aortic coarctation referred for cardiovascular magnetic resonance imaging to a tertiary center. Pediatr Cardiol. 2011;32:1120-1127. doi: 10.1007/s00246-011-9981-0.

2. Stout KK, Daniels CJ, Aboulhosn JA, et al. 2018 AHA/ACC guideline for the management of adults with congenital heart disease: executive summary. J Am Coll Cardiol. 2019;73:e129-e131. doi: 10.1016/j.jacc.2018.08.1028.

3. Warnes CA, Williams RG, Bashore TM, et al. ACC/AHA 2008 guidelines for the management of adults with congenital heart disease. J Am Coll Cardiol. 2008;52:e143-e263. doi:10.1016/j.jacc.2008. 10.001 .

4. Rudolph AM, Heymann MA, Spitznas U. Hemodynamic considerations in the development of narrowing of the aorta. Am J Cardiol. 1972;30:514-525. doi:10.1016/0002-9149(72)90042-2.

5. Russell GA, Berry PJ, Watterson K, Dhasmana JP, Wisheart JD. Patterns of ductal tissue in coarctation of the aorta in the first three months of life. J Thorac Cardiovasc Surg. 1991;102:596-601.

6. Sheikhzadeh A, Giannitsis E, Gehl HB, Maring C, Stierle U. Acquired thromboatheromatous coarctation of the aorta: acquired coarctation of the aorta. Int J Cardiol. 1999;69:87-91. doi:10.1016/ S0167-5273(99)00033-9.

7. Pagni S, Denatale RW, Boltax RS. Takayasu's arteritis: the middle aortic syndrome. Am Surg. 1996;62:409-412. 